\title{
Can social capital play a role in contracting services of family doctors in China? Reflections based on an integrative review
}

Xinglong $\mathrm{Xu}^{1}$, Henry Asante Antwi ${ }^{2,3^{*}}$, Lulin Zhou ${ }^{1}$, Tehzeeb Mustafa ${ }^{1}$ and Ama Boafo-Arthur ${ }^{4}$

\begin{abstract}
Background: The family doctors' contract service problem is not about government management alone, but an interaction of a complex social environment. Consequently, the effect of contracted services of family doctors not only depends on policy incentives but also needs to win the participation, acknowledgement, and confidence of community residents. The purpose of this integrative review is to examine whether there is any significant evidence that social capital in the form of social networking groups and other forms of social groups have any positive impact on the acceptance and the effectiveness of family doctors' contractual services.
\end{abstract}

Method: Research on qualitative, quantitative and hybrid methods published in peer-reviewed journals on the social capital role in the process of contract service of family doctors were eligible for inclusion. In view of the increasing attention paid to the contract service effect of family doctors during this period, a 10-year time scale was selected to ensure full coverage of relevant literature in the same period. In total, 809 articles were determined in the database retrieval results which were downloaded and transferred to the Mendeley reference application software.

Results: Twelve articles met the inclusion criteria for this integrative review and the quality of the included studies were assessed using the published criteria for the critical appraisal of quantitative and qualitative research methods. Majority of the articles assessed reported that there was evidence of a positive link between social support, especially a sense of belonging and the presence of regular family doctors. The influencing factors of patients' contract behavior of studies conducted in China were social interaction of social capital, acceptance of the first contact in the community, year of investigation, and exposure to the public.

Conclusion: The study affirms previous studies that suggest that social resources have the propensity to improve relationship between patients and clients and between doctors and peers for the benefit of the patients and the stability of the overall healthcare system. Through the integration of various social resources family doctor systems accelerate the development of community construction. These social capital (social network groups) can guide residents to use family doctor services to maintain health. Social capital can also help residents have a regular and reliable family doctor.

Keywords: Family doctor, General practitioners, Integrative review, Social capital, Social network, General practice, Family physician

\footnotetext{
*Correspondence: 5103150217@stmail.ujs.edu.cn

${ }^{2}$ Center for Health and Public Policy Res, earch, Jiangsu University, 301

Xuefu Road, Zhenjiang, Jiangsu, P.R. China

Full list of author information is available at the end of the article
} original author(s) and the source, provide a link to the Creative Commons licence, and indicate if changes were made. The images or other third party material in this article are included in the article's Creative Commons licence, unless indicated otherwise in a credit line to the material. If material is not included in the article's Creative Commons licence and your intended use is not permitted by statutory regulation or exceeds the permitted use, you will need to obtain permission directly from the copyright holder. To view a copy of this licence, visit http://creativecommons.org/licenses/by/4.0/. The Creative Commons Public Domain Dedication waiver (http://creativeco mmons.org/publicdomain/zero/1.0/) applies to the data made available in this article, unless otherwise stated in a credit line to the data. 


\section{Background}

China continues to make significant strides in her effort to reform its primary healthcare system to provide effective and efficient patient care services to its citizens. The primary healthcare system in China is divided into rural and urban components but the organizations are very similar [38]. Generally, healthcare is provided through a three-tiered system. The first tier is village clinics and medical centers often manned by the barefoot doctors and physician assistants due to the absence of highly qualified medical personnel. The second tier is made up of township and community health clinics that function primarily as out-patient clinics. These centers also serve as referral centers for village clinics and often attract fairly qualified medical professionals. The county hospitals with very qualified medical practitioners complete the third level of health service delivery in Chinese suburban regions. Similarly, the urban health service delivery starts with factories and neighborhood health stations. These are supervised by the district hospital while the most serious cases were handled by municipal hospitals and tertiary hospitals [20].

Nevertheless, China's healthcare system in general and primary healthcare in particular still faces challenges in structural characteristics, incentives and policies, and quality of care, all of which diminish its preparedness to care for its large, aging population amidst the growing prevalence of chronic non-communicable diseases. With an ever-increasing healthcare demands, individuals started contracted their own family physicians hence the family doctor contract services. To that extent, China introduced the family doctor system to strengthen its primary healthcare delivery services but the family doctor system is plagued with several social problems that have rendered it less attractive to both doctors and patients. The family doctor system is assailed with community health resource constraints, unmotivated doctors, lack of social participation etc. [30].

For example, Binder [2], many Chinese are not aware of the benefits of family doctor contract services. The policy of government at the onset was to encourage more people to enroll with much investment on effective strict supervision and quality family doctor contract services [6]. Naturally, the confidence of residents eroded with persistent unsatisfied medical services [6]. Moreover, only few doctors are willing to accept family doctor services in China due to poor remuneration, excessive supervision and poor career progression [20,30]. As explained in [30], effective family doctors services depends on both policy incentives and winning the participation, acknowledgement, and confidence of community residents [30].

According to Zhou, et al. [40] social capital can be an effective way to resolve some of the social challenges affecting effective family practice in China. The concept of social capital has evolved through series of scholarly research studies across the globe. Between 1700 and 1900, Adam Smith, Marx Rousseau, Tocqueville etc. established the basic tenets of social capital theory through the social exchange theory and the psychological construct theory. Hanifan [17] first used the term "Social Capital" to refer to the goodwill, mutual sympathy, fellowship, and social intercourse that exist among families and group of individuals and families. Jacobs [19] also defines social capital as a tool for strengthening urban vitality. Thus social capital is social network used in stimulating positive relationships. The modern concept of social capital is derived from the ground breaking works of Coleman [7] and Bourdieu [3].

According to Coleman [7] social capital are features of social organizations such as networks, norms, and social trust that facilitates coordination and cooperation for mutual benefits. Bourdieu [3] on the other hand explains social capital as the aggregate of the actual or potential resources which linked to possession of a durable network of more or less institutionalized relationships of mutual acquaintance and recognition. In the midst of the insecurities of family doctor contract services, both doctors and patients need social capital to maintain their trust in the system. Doctors need social support from supervisors and colleagues to openly communicate their grievances, reduce burnout, improve wellbeing and become more engaged in the practice. On the part of patients, Shang et al. [30] discloses, traditionally, family doctors have been seen as "people doctors", rather than "disease doctors". They are expected to form informal social relationships with their patients as part of both preventive and medical care services. They must bring patients to the doorstep of the medical services through warmth, trust, mutual help, shared value and coordination of communal healthcare tasks. Therefore, social capital will have an impact on the effect of contracted services of family doctors $[20,26,30]$.

Since May 2016, the Chinese government has expansively promoted family doctor contracted services throughout the country and made it the main task of expanding the transformation of the clinical care and healthcare system in this new era [21] but effective family practice goes beyond setting up a system. It also involves, having sound personnel, effective incentive methods, smooth referral channels, and service-oriented residents' needs but these are poorly integrated in China's family doctor system [34]. The after-effect of COVID-19 has increased the urgency for China to strengthen it family doctor contract services. China believes that family doctor contract service has a great influence on the ability of health service at the 
grass-roots level, and its effectiveness and accessibility are the keys to the realization of universal health coverage [13]. This review summarizes the qualitative and quantitative results from articles and the effective impact of social capital (social network groups) in the contracted services of family doctors and its applicability in China. This paper also reviews the influence of social capital on the form and effect of family doctor services. To further explore the mechanism and management of social capital in the contracted services of family doctors.

\section{Methods}

This particular integrative review was steered by the updated version of Whittemore and Knafl's comprehensive methodology review outline. This is a description of the mythological approach to integrative review that was published in 2005. Since then the model has become the basic benchmark and the conceptual structure of most integrative review due to its robustness especially in the field of healthcare. The model combines both quantitative and qualitative study findings on targeted topics and provides a comprehensive understanding of the review issues. The framework includes five stages, such as identification of the research problem, articles retrieval, evaluation of the data retrieved, analysis of the retrieved data, and the presentation of the findings [25]. The PRISMA guidelines were consulted to augment the process of reporting the study's findings in order to ensure robustness of inference. The extent to which each of these stages were applied to this study is highlighted in the next sections.

\section{Identification of the problem}

The purpose of the study is to examine whether there is any significant evidence that social capital in the form of social networking groups and other forms of social groups have any positive impact on the acceptance and the effectiveness of family doctors' contractual services. It also seeks to recommend any practical learning suggestions that can be applied to healthcare management projects, such as the family doctor services policy development in China. The main purpose of this integrative review is to thoroughly identify, select, evaluate/examine critically, and synthesize articles on social capital which can positively affect the effect of family doctor's contract services.

\section{Literature Search}

A strict inclusion and exclusion criteria was set in the search for qualifying articles. Firstly the paper should have been peer reviewed published, abstracted or indexed in a recognized database such as such as Medline, Web of Science, Science Direct and PubMed. Pre-print databases with articles under review in high impact factor journal were also consulted for current information that is in the review process. Secondly, the articles should have been published in English language. The studies also included quantitative research, qualitative research and mixed research studies in so far as the focus is on the role of social capital and family doctor contract service. The included articles must primarily focus on China or compare the case of China and other countries. This criterion notwithstanding, some studies that were not China based were included because they have significantly explored and advanced the frontiers of social capital in family medicine. They include studies Small et al., [32] that highlight the benefits of peer support networks established in conjunction with doctors to help needy doctors and patients without access important medical information.

Another inclusion criterion was that the field of medicine is a highly specialized area hence specialized professional groups abound. Thus journals or publications by professional groups within the healthcare sector that bothered on family practice were also consulted. The family doctor contract services in China do not have a long history but interest dates back to more than a decade. For this reason, studies spanning a ten year period up to 2019 were selected to ensure full coverage of relevant literature in the same period Table 1.

In total, 809 articles were determined in the database retrieval results which were downloaded and transferred to the Mendeley reference application software. Repeated articles (353) were deleted after which all the authors reviewed the copies of the papers and discussed their differences until a consensus was reached. After deliberation, 456 articles were further deleted. Article titles and their summaries were examined by XX and HAA for their importance based on the exclusion and inclusion criteria. After the screening, the two authors discussed

Table 1 Terms used for the literature search

\section{Article Search Terms}

"family doctor" OR "family physician" OR "general practice" OR "general practitioner" OR "family practice" OR "social capital" OR "social network" OR "family doctor" AND "social capital" OR" primary care" AND "social capital" OR "family physician" AND "social capital" OR "service form for family doctor" OR "service results for family doctor" 
their outcome with the other authors and 31 articles were selected for full-text assessment. On this basis, the authors further screened the above-mentioned articles around the research topic and objectives and forwarded 12 papers for analysis (Fig. 1).

\section{Data extraction and evaluation}

The assessment of the 12 full-text articles composed of 2 level evaluations.

(1) The first stage evaluation involved the exclusion of studies using the layout for the exclusion and inclusion criteria rules. In this level, 12 articles were selected based on the inclusion criteria. These comprise of 1 qualitative and 11 quantitative studies as indicated in (Fig. 1). Data were extracted on the study objectives, sampling strategy, sample size, study design, data collection technique, strengths and limitations, key findings, and analytical approach of the studies (Table 2).

(2) The evaluation of the second level involved the critical appraisal (XX, ZLL, HAA, and JOM) to determine the methodological quality of the included studies. Due to the variety of methodologies and designs, two method-specific tools were identified to assess the quality of evidence. For qualitative studies, the Critical Appraisal Skills Programme (CASP) [9] tool was used (Table 3) and the Rees et. al. [28] survey checklist (Table 4) was utilized for cross-sectional studies. Each criterion was recorded as "Yes" or "No" or "Clear" or "Unclear" and results of appraisal were discussed

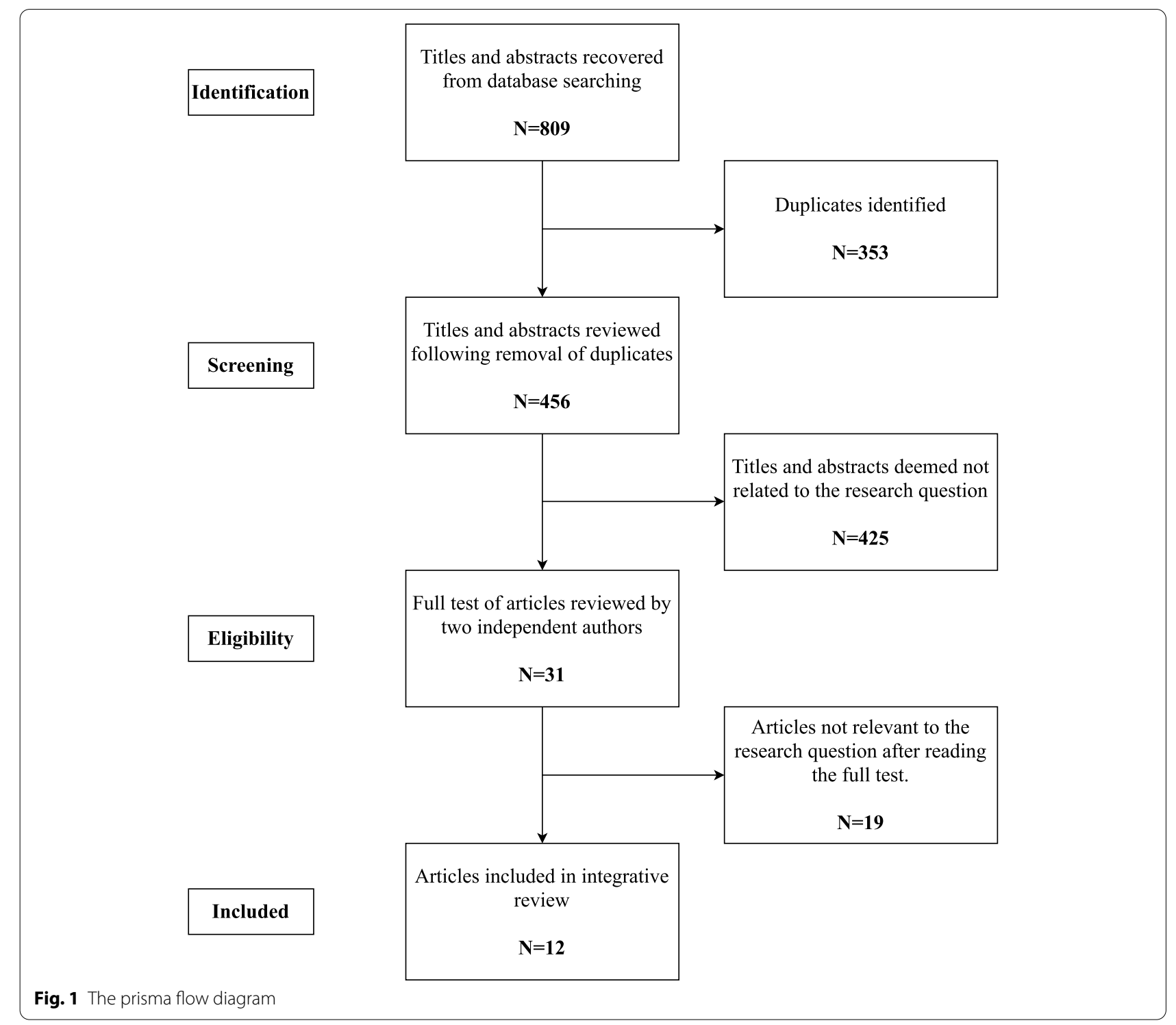




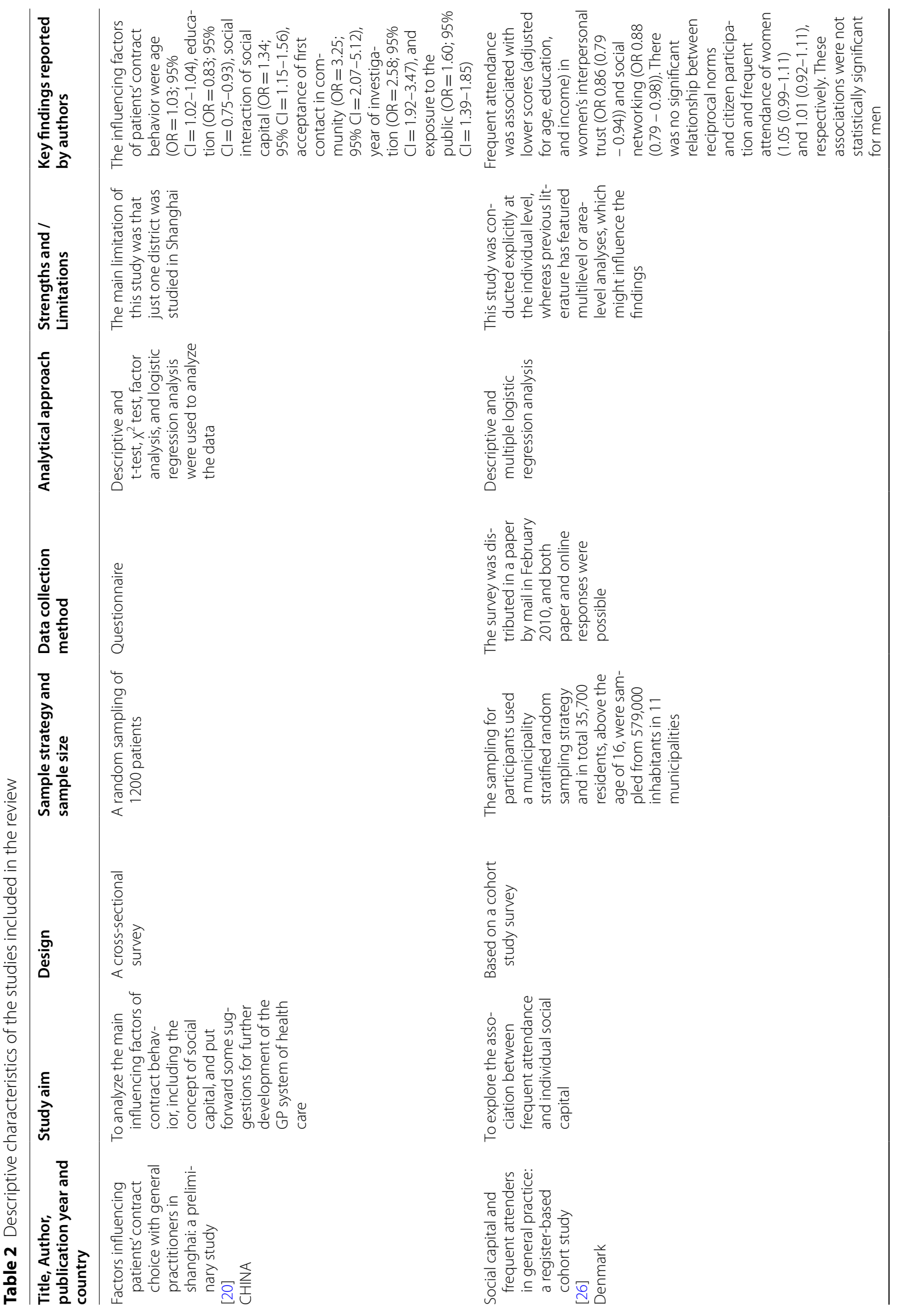




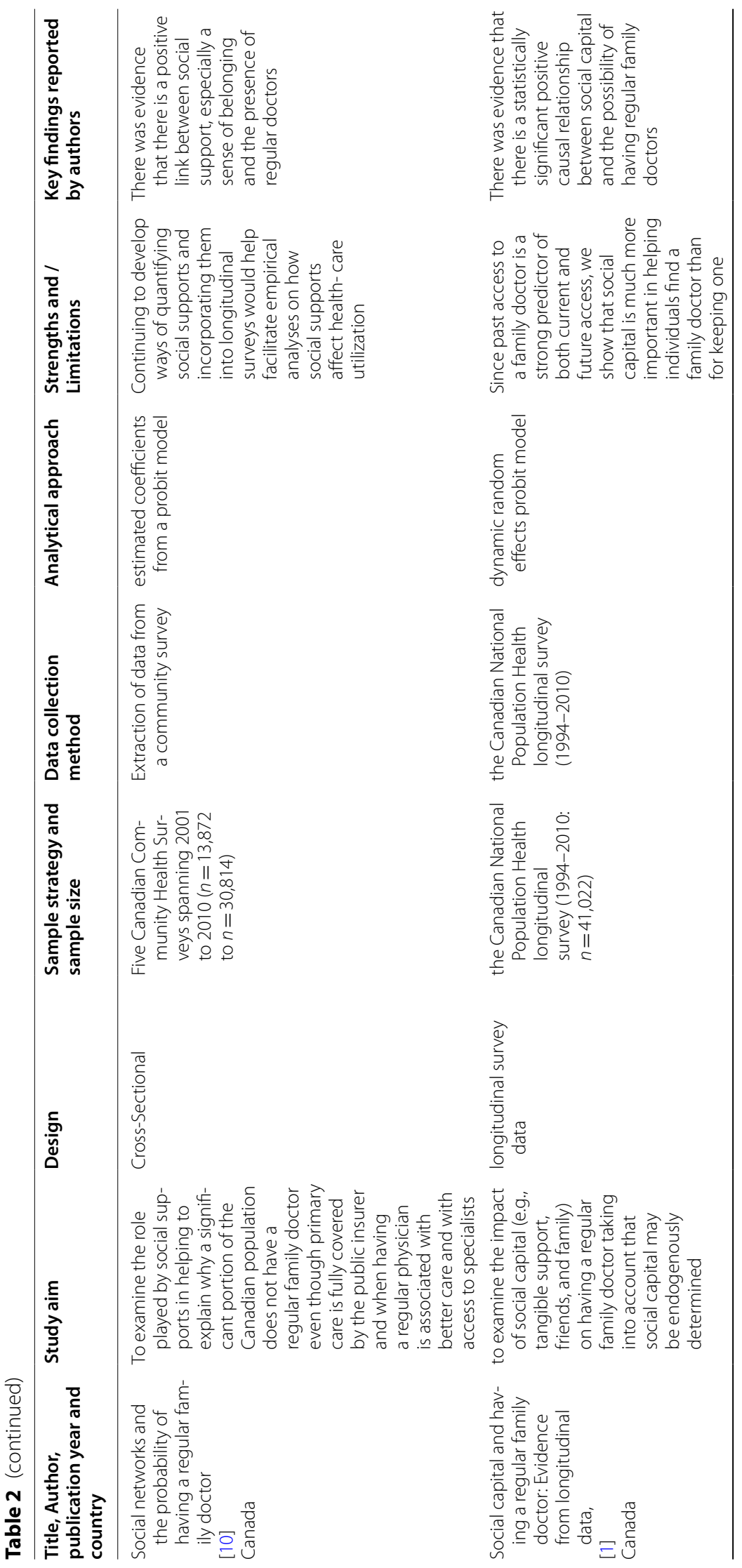




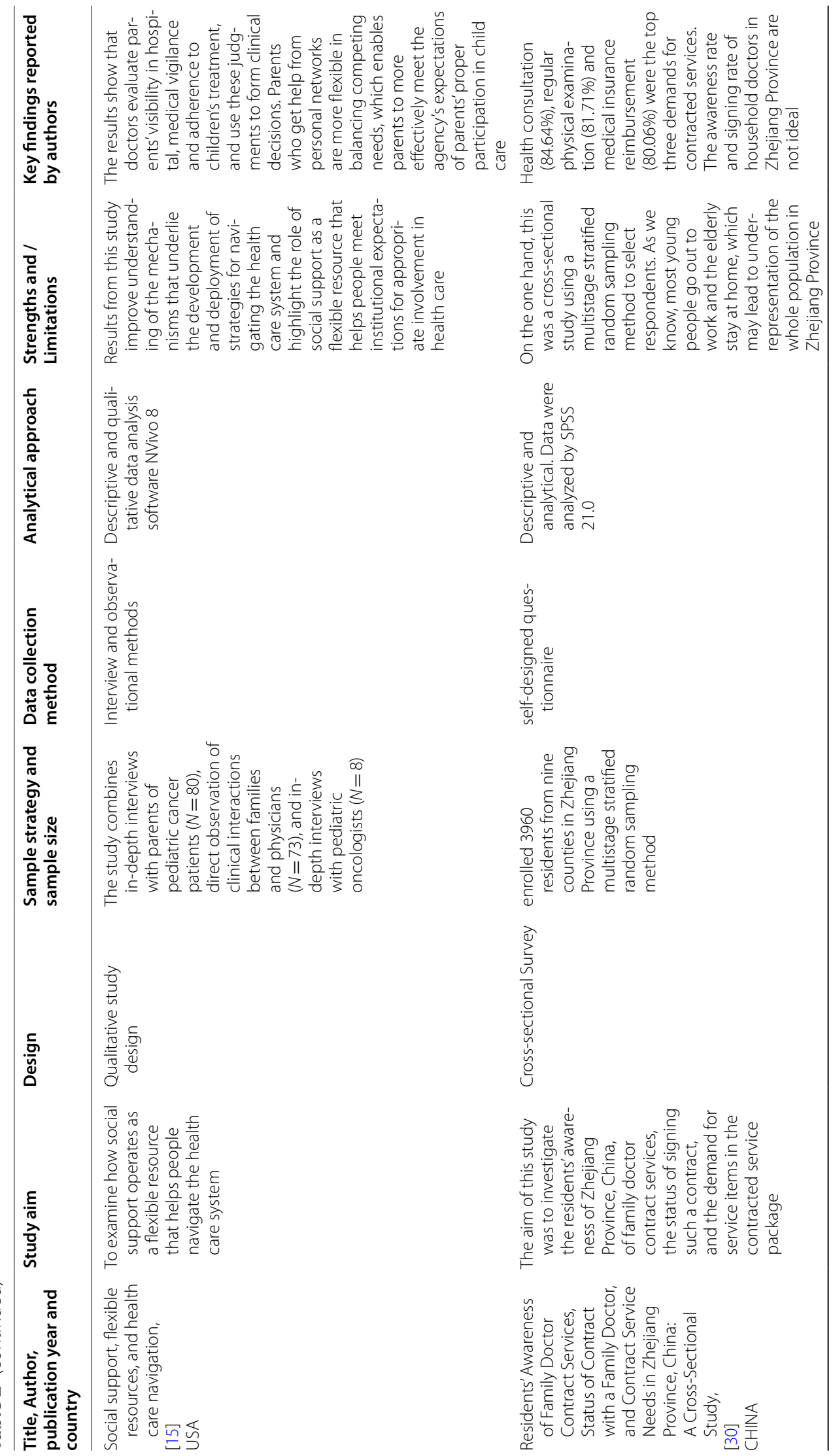




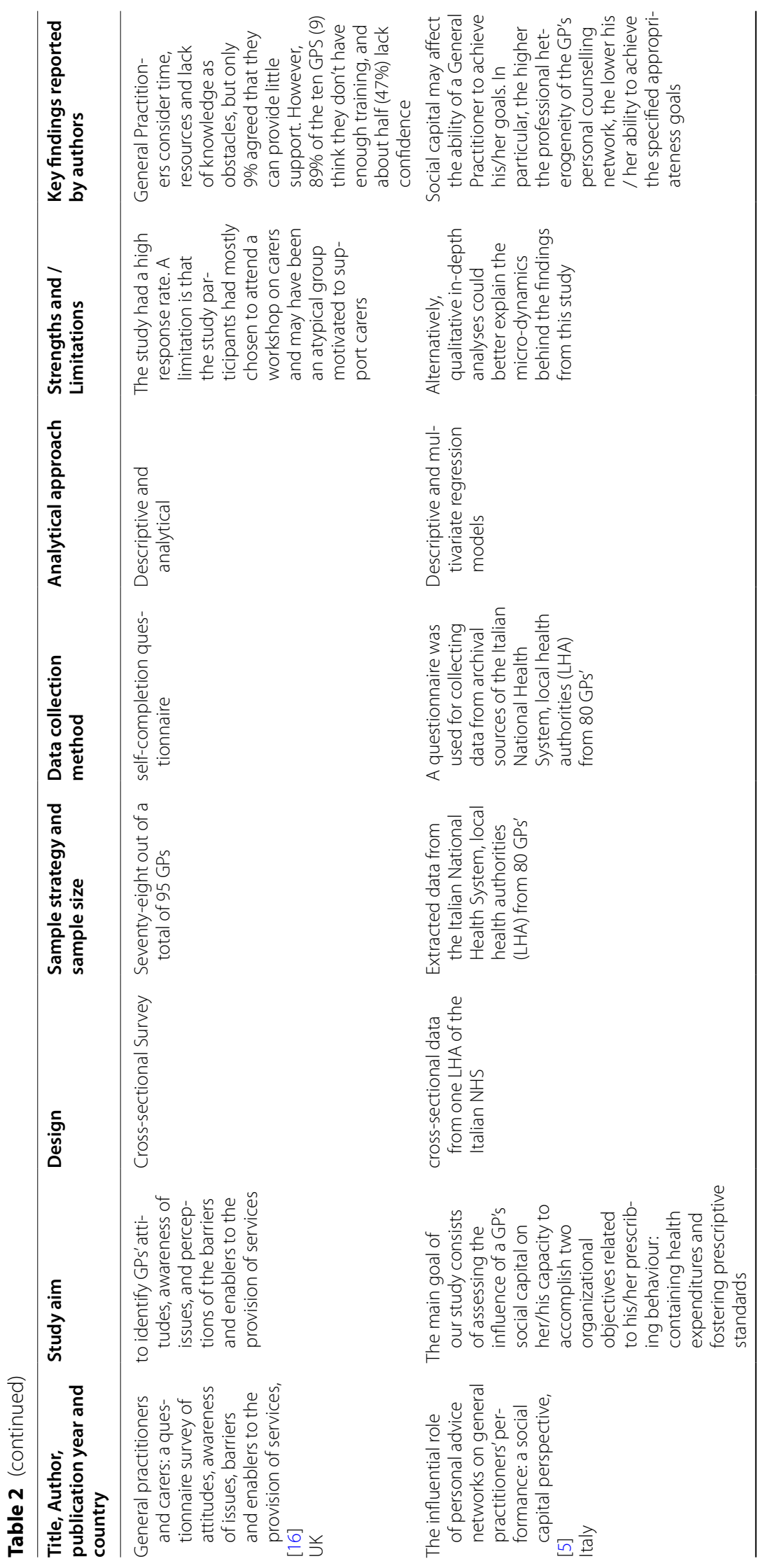




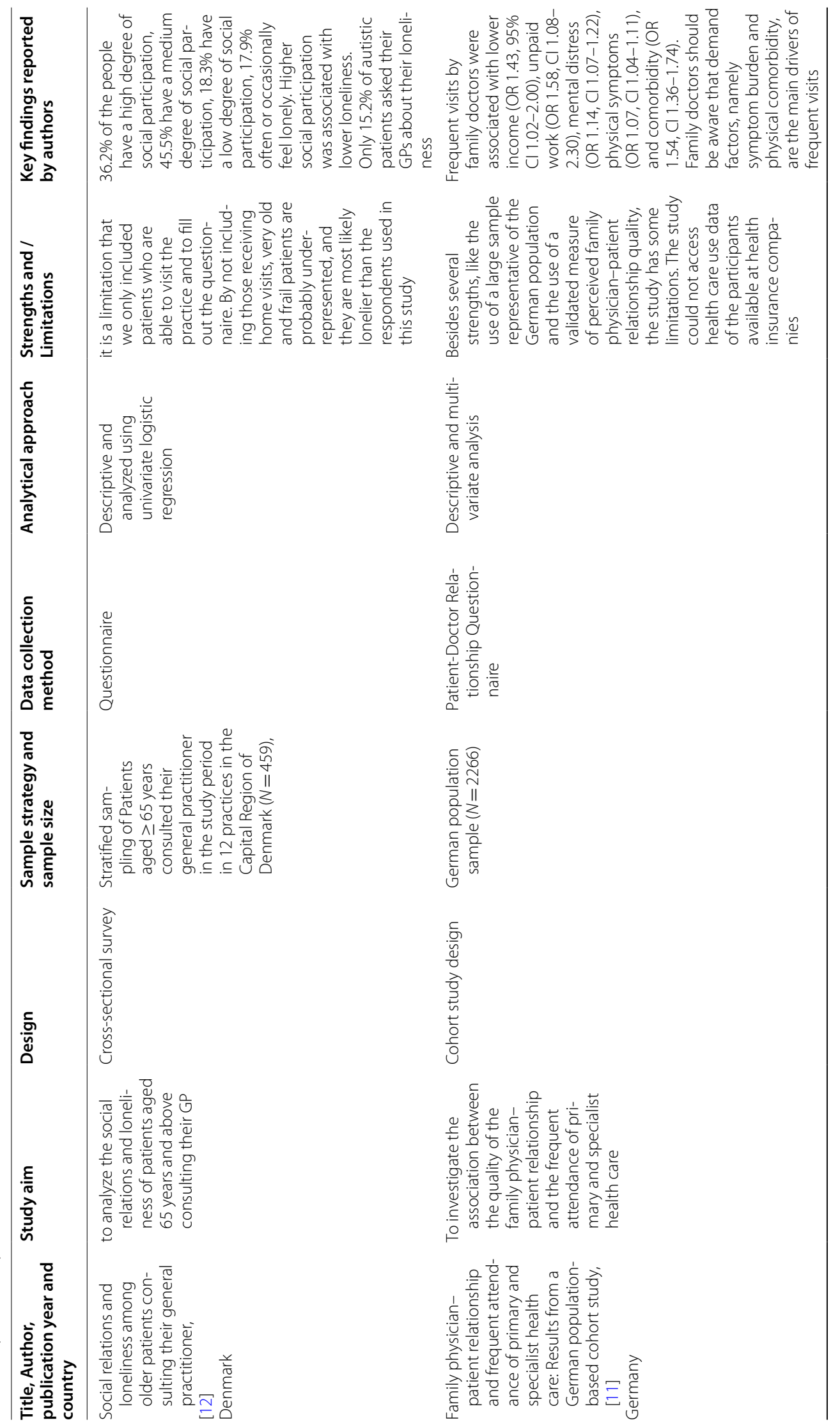




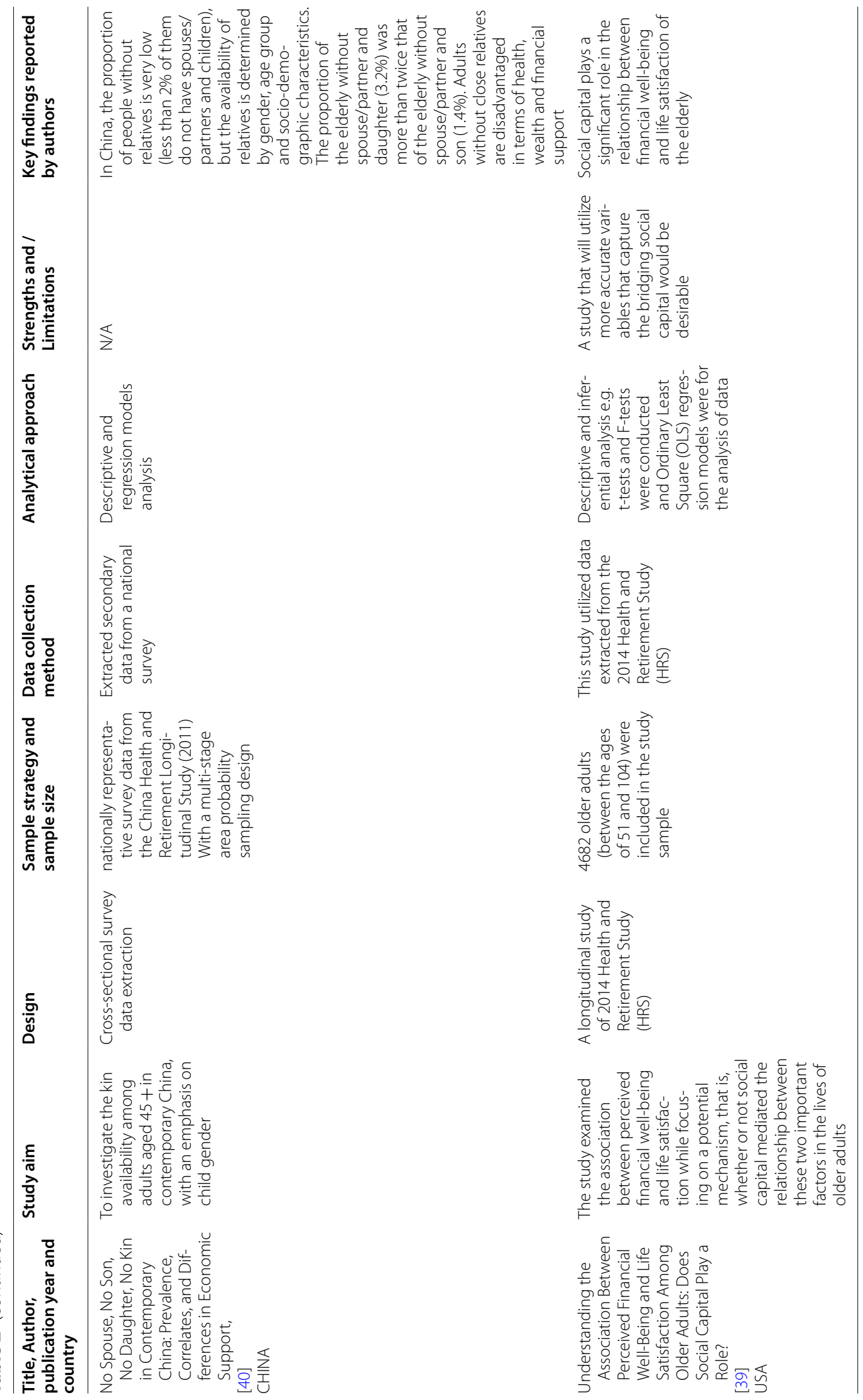


between XX, ZLL, HAA and JOM with discrepancies resolved by consensus. Overall studies were found to be of good methodological quality with the only qualitative study recording nine out of the ten appraisal criteria (Table 3) and quantitative studies recording between 11 and 14 of the total appraisal score (Table 4). All the studies have determined the research objectives, proved the appropriateness of the design, used a clear sampling strategy, made a clear statement of the research results, and outlined the value of its research. In terms of the quantitative studies, response rates varied between 65.5\% [26] to $97.75 \%$ [30] and only a study attempted to contact non-responders [26]. Most of the studies were limited to the purposive sampling method (Table 4). Four studies did not provide sufficient information to appraise the reliability of the measurement items (Table 4). Five of the quantitative studies were unclear regarding ethical approval or informed consent from an ethical committee (Table 4). Similarly, the conclusions of all quantitative studies are supported by data used for analysis, and the objectives of the study are described (Table 4). Qualitative research is valuable and provides details that fully consider the relationship between researchers and participants (Table 3).

\section{Retrieved data analysis}

In light of the heterogeneity of the literature contained, the results of each study were examined [4], because conclusions can be drawn based on common factors [22]. Procedures which were used to carry out the thematic examination were guided by Smith et al. (V. [33], and Lucas et. al. [22].

\section{Findings presentation}

The summary of the findings from the 12 studies included in the review is depicted in Table 2. The selected papers were mainly research works conducted in the USA [15, 39], Denmark [12, 26], Canada [1, 10], China [20, 30, 40], UK [16], Germany [11], and Italy [5]. Out of the eleven quantitative studies; seven of them were cross-sectional in nature $[5,10-12,16,30,40]$; two were based on data extracted from a cohort studies [11,26] and the other two studies were based on longitudinal data [1, 39]. The sample size of these studies varied from 78 to 4682 respondents.

A study reported that the quality of social capital may invariably obstruct a General Practitioner's propensity to achieve specific targets. Specifically, it is demonstrated that when a GP is networked in a highly heterogeneous social or professional group, the advice from this group can limit the extent to which he can make accurate personal prescription decisions [5].

Causes and affect relationships on family doctor contract services is also well established and discussed in the retrieved literature. Some studies confirmed the effect of social capital on the relationship between financial well-being and life satisfaction of the elderly [39]. Two studies retrieved from Canada also reported that there was evidence of a positive linkage between social support, especially a sense of belonging and the presence of regular family doctors $[1,10]$. The low level of social participation affected family doctor services while higher social participation was associated with lower loneliness in studies conducted in Denmark [12, 26]. The effect of socio-economic on patient-family doctor behavior is also addressed by the studies. In the extant literature outside China, the main social factors that have been explored include education, income, gender and age. In the particular case of studies in China, the common social factors that moderates the social capital and doctor patient relationship were age, education, social interaction of social capital, acceptance of the first contact in the community, year of investigation, and exposure to the public [20, 30, 40].

Frequent attendance at GPs offices is a long standing critical issue for GPs because of its capacity to unduly impose excessive burden on the doctor. Moreover, frequent patient visits can be a huge drain on the limited healthcare resources. The interplay between social capital and frequent doctor visits came up in some of the reviewed studies especially in the context of Europe. One study sought to examine whether social capital resources can be harnessed to support or reduce frequent use of general practice, which may in turn lower the frequency

Table 3 Methodological quality of qualitative studies

\begin{tabular}{|c|c|c|c|c|c|c|c|c|c|c|c|}
\hline Study & 1 & 2 & 3 & 4 & 5 & 6 & 7 & 8 & 9 & 10 & Total Scores \\
\hline E. Gage-Bouchard, [15] & Yes & Yes & Yes & Yes & Yes & Yes & Unclear & Yes & Yes & Clear & $9 / 10$ \\
\hline
\end{tabular}

Keys: "1. Is there a clear statement of the purpose of the study?; 2 . Whether the qualitative method is appropriate?; 3 . Whether the research design is suitable for the research purpose?; 4 . Whether the recruitment strategy is suitable for the purpose of research?; 5 . Can data collection methods solve research problems?; 6 . Whether the relationship between researchers and participants is fully considered?; 7. Whether moral issues are taken into consideration?; 8 . Is data analysis rigorous enough?; 9. Whether there are clear findings?; 10 . How valuable is this research?" 
Table 4 Methodological quality of quantitative studies

\begin{tabular}{|c|c|c|c|c|c|c|c|c|c|c|c|c|c|c|c|}
\hline Study & $1 \mathrm{a}$ & $2 a$ & $2 b$ & $2 c$ & $2 d$ & $3 a$ & $3 b$ & $3 c$ & $4 a$ & $4 b$ & $5 a$ & $6 a$ & $7 a$ & $8 a$ & Total Scores \\
\hline Jing et. al. [20] & Y & Y & Y & Y & $\mathrm{N}$ & Y & Y & Unclear & Y & Y & Y & Y & Y & Clear & $12 / 14$ \\
\hline Pasgaard et. al. [26] & Y & Y & Y & Y & Y & Y & Y & Y & Y & Y & Y & Y & Y & Clear & $14 / 14$ \\
\hline Devlin et. al. [10], & Y & Y & Y & $\mathrm{N}$ & $N$ & Y & Y & Unclear & Y & Y & Y & Y & Y & Clear & $11 / 14$ \\
\hline Bataineh et. al. [1] & Y & Y & Y & $\mathrm{N}$ & $\mathrm{N}$ & Y & Y & Unclear & Y & Y & Y & Y & Y & Clear & $11 / 14$ \\
\hline X. Shang et. al. [30] & Y & Y & Y & Y & N & Y & Y & Y & Y & Y & Y & Y & Y & Clear & $13 / 14$ \\
\hline Greenwood et al. [16] & Y & Y & Y & Y & $N$ & Y & Y & Y & Y & Y & Y & Y & Y & Clear & $13 / 14$ \\
\hline Calciolari et. al. [5] & Y & Y & Y & Y & $N$ & Y & Y & Y & Y & Y & Y & Y & Y & Clear & $13 / 14$ \\
\hline Due, T. D., et. al. [12] & Y & Y & Y & $\mathrm{N}$ & N & Y & Y & Unclear & Y & Y & Y & Y & Y & Clear & $11 / 14$ \\
\hline A. Dinkel et. al. [11] & Y & Y & Y & Y & $N$ & Y & Y & Y & Y & Y & Y & Y & Y & Clear & $13 / 14$ \\
\hline Z. Zhou et. al. [40] & Y & Y & Y & $N$ & $N$ & Y & Y & Y & Y & Y & Y & Y & Y & Clear & $12 / 14$ \\
\hline J. Yeo and Y. Lee, [39] & Y & Y & Y & N & $\mathrm{N}$ & Y & Y & Y & Y & Y & Y & Y & Y & Clear & $12 / 14$ \\
\hline
\end{tabular}

Key:

$\mathrm{Y}$ - for Yes, $\mathrm{N}$ - for No. "A. Is the result valid? 1. Objectives: 1a. Is the research objective clear? 2. Design: 2a. Whether the study design is suitable for the target? 2b. Does this theme represent all interested groups? 2c. Whether it has obtained moral/ethical recognition? $2 \mathrm{~d}$. Whether to take measures to contact non-responders? 3. Measurement and observation; $3 \mathrm{a}$. Whether it is clear what has been measured, how to measure and what the result is? $3 \mathrm{~b}$. Is the measurement valid? $3 \mathrm{c}$. Is the measurement result reliable? B What are the results; Presentation of results; $4 \mathrm{a}$. Whether the basic data is fully described? $4 \mathrm{~b}$. Whether the results are clear, objective and detailed enough for the readers to make their own judgment? Analysis; 5a. Is the method used suitable for the collected data? C Will the results help locally? 6 Discussion; 6 a Is the outcome of the discussion related to the existing knowledge about the discipline and research objectives? 7 Interpretation; 7 a. Is the author's conclusion confirmed by data? 8 Implementation; 8a Can any necessary changes be implemented in practice?" Rees et al. [29]

to attend hospitals [26]. It emerged from this study that social capital deficit in some cases can induce frequent GP visits.

A German study linked the frequent visit of family doctors to their lower-income level [11]. The sample size of the qualitative study was 80 participants, including 59 women and 21 men [15]. This particular article reported on the examination of "how social support operated as a flexible resource that might help people navigate their health care system in their locality". The study used interview and observational methods for data collection. The study also combined in-depth interviews and direct clinical interactions observations among families and their medical doctors. Descriptive and qualitative data were analyzed with the statistical software, NVivo version 8 [15]. The results from this study reported having improved the understanding of the mechanism that inspire the expansion and the distribution of the policies for steering the health care system. It further highlights the impact of social network support as a flexible resource that helped people met their organizational prospects for suitable involvement in health care [15].

To evaluate the quality of the studies, the Mixed Methods Appraisal Tool (MMAT) was applied as shown in Table 4. Pluye \& Hong [27] explains that the MMAT tool helps to provide quality appraisal for quantitative, qualitative and mixed methods to be included in systematic reviews. In the MMAT the least paper met 11 out of the 14 quality benchmarks ( 3 articles) whereas the highest obtained 14 out of 14 quality benchmarks (1 article). This represents $25 \%$ and $8.3 \%$ MMAT quality respectively. While three other articles (also representing 25\%) obtained met 12 of the 14 MMAT quality benchmark, the remaining 5 articles representing $41.6 \%$ obtained 13 out of the 14 MMAT quality benchmarks. The most frequent weaknesses related to lack of discussion on the reason for studying specific organisations, the influence of the organisation on the research and researcher influence in qualitative and mixed methods studies. There were also issues with lack of a clear description of the sampling process of respondents adopted by authors in quantitative studies and sub threshold rates for acceptable response or follow-up in non-randomized quantitative studies were also recorded as major weaknesses of the quantitative research. Most of the studies had support from funding agencies or organisations for whom the research outcome serve their interest. Thus the influence of such organisations in the conduct of the research was not disclosed by the researchers.

\section{Results}

\section{Identification of social capital/network influence of family doctor acceptance}

The theme identification of social capital /network influence of family doctor acceptance explores.

(1) Benefits of having a family doctor

(2) Benefits of belonging to social capital or social network

(3) Influence of social capital or social network groups on accepting a family doctor 
(4) Family doctor policies

(5) Barriers to the family doctor contract services acceptance

\section{Benefits of having a family doctor}

GPs play a unique role in dealing with social relations and loneliness [12]. GPs identified the important influence of general practice in supporting patients but also wished to get more training and support [16]. The family doctor is the first call point in an emergency situation. There is evidence that finding a regular family doctor can improve health [1]. Better continuity and quality of care, as well as improved health, are some of the overall benefits of having a regular family doctor [1].

\section{Benefits of belonging to social capital or social network group}

Undoubtedly, in terms of quality of life, morbidity, and mortality, the community social network relationships are very vital for the people in the community. This applies especially to the elderly [12]. The health of the people in the community, as well as their social network groups, are interconnected. In recognition of this social fact, over the past decade, there has been increasing conceptual and empirical attention to the impact of social networks on health [31]. According to a study conducted by E. A. Gage-Bouchard [15], most parents who received aids through their personal social networks were most comfortable in balancing their competing demands. This enabled them to effectively comply with their agencies' hopes of parents' proper participation in child care [15]. In this way, social support provided some families with flexible resources, which enabled them to acclimatized to the needs of caring for children with cancer more quickly. It also raised a fruitful social relationship between parents and their medical care providers which played an active impact in the health of their children [15]. Notably, quite a number of studies on social support and health have shown that emotional, logistical, information and financial support from personal networks enhance people's coping choices in managing serious diseases [31, 35].

\section{Influence of social capital or social network groups on accepting a family doctor}

Some aspects of women's social capital groups are related to regular participation in the acceptance and use of GPs or family doctors [26]. On the contrary, men's social capital has nothing to do with their acceptance of family doctors or GPs. This shows that there are various and varied relationships between social capital and the gender of regular attendance [26]. In Zhejiang Province, China, for instance, the level of family doctor contract services (FDCS) awareness and the signing rate of family doctors are not the ideal, aside from that there is still a lot to be done for further improvement [30]. However, age, educational level and chronic medical history were some of the factors identified to be influencing residents' awareness of FDCS. Concurrently, residents' understanding of FDCS also affects their signing rate with family doctors. Surprisingly, patients who signed the agreement with the family doctors had a large request for FDCS. But the demand rate of residents with different social and demographic characteristics was different for different FDCS projects. Therefore, this is a call for the government to strengthen the policy support, strengthen the information campaign, expand the service scope, and provide more attractive service items in order to encourage the expansion of FDCS in China [30]. Residents should be allowed to choose a family doctor of their choice to sign the contract with. In addition, they should be allowed to also choose the projects they need when signing a contract with family doctors. The family doctors should also offer better services to the satisfaction and fulfilment of the residents [30].

There is evidence that a positive link exists between social support (especially a sense of belonging) and maintaining a consistent medical doctor [10]. There is also evidence that shows a significant positive causal association between social capital and the likelihood of attaining a regular family doctor [1]. Nevertheless, social capital was reported by a study as being much more important to helping individuals to find family doctors than to keeping them [1]. Undoubtedly, the influence of social capital (social networking groups) in the relationship between economic well-being and the life satisfaction of the elderly was statistically significant [39]. It is worth noting that obtaining social capital through strong family relationships and active social networks may decide the life satisfaction of the elderly [39].

\section{Family doctor policies in China}

Under the dual system of government guidance and market regulation, FDCS improves the quality of medical services through policy guidance and individual independent contracting [30]. Based on the governmentled contract to provide a certain limit of service content, standardize service pricing, maintain service order, and adjust the exclusive personalized service according to the market demand. This system not only produces a unique medical service model but also faces a huge 
Governance Dilemma of doctor-patient trust and risk resolution. In order to give social power, give full play to the effective role of social organizations, build an interactive, integrated and trusted network governance structure, and straighten out the role relationship between the government and the market, it has an important role in promoting the integration of market and social resources across borders and regions and promoting the social empowerment of the government. Therefore, this policy is considered to be an effective way to promote the development of family doctor relationship under contracted services.

\section{Barriers to the FDCS acceptance}

Based on self completed questionnaire, Greenwood et al., [16] investigated the attitude of GPs to carers, their awareness and knowledge of issues affecting these carers as well as the barriers that hinder the effective functioning of their supporting carers. The GPs in this study indicated that the lack of time, resources and knowledge of inpatients or patients were some of the obstacles for patients or carers to accept the FDCS [16]. These GPs also recognize that they also have a vital role to play in supporting carers [16]. The promotion and coverage of FDCSs will be expanded, and personalized contract programs will be launched to meet the needs of different social network groups, so as to promote the rapid development of family doctor's contracts in all provinces of China [30]. The factors that affect residents' trust and satisfaction are family doctors' medical service skills, residents' familiarity with family doctors, communication ability of family doctors, patients' medical care concept and medical environment of community hospitals [8]. The other factors that influence the work attitude and activities of family doctors' services are work task and income level, the management of community health centre, and the understanding of their own occupation and service objective attitude [8]. The family doctor system should take the community as the carrier, integrate various social resources, improve the doctor-patient relationship, cultivate social network groups in the community, and accelerate the development of community construction. In addition to the support of hardware facilities and supporting policies, social capital, and other soft environments are of great significance to the establishment of FDCS [8].

\section{Discussion}

The main aim of this integrative review report is to determine if the benefits of social networking groups tend to help or enable residents to better understand the family doctors' policies and make them healthy by using FDCS. It is of no doubt that a solid family doctor-patient relation doesn't certainly prevent frequent visits to a doctor's office or to make appointments with a specialist. It does not also imply that GPs should not be concerned in building robust relationships with patients, as strong family doctor-patient relationships are related to other essential issues such as patients' compliance and satisfaction $[11,14]$. Over the past 20 years, the issues of social capital have been linked to a diversity of healthcare outcomes such as causes of mortality [18, 24]. Social capital(interpersonal relationships) is a complicated imaginary structure with a very intricate pedigree [23]. In fact, the understanding of social capital can be seen as the actual or likely benefits that individuals can obtain through their social network, such as nursing, advice, emotional and financial support. Therefore, in terms of health care exploitation, we expect closer ties and greater impact on their behaviour. Due to the fact that health is often discussed with family members and other close confidants, leading to the use of informal resources, which may reduce the desire for formal healthcare system. However, the relationship between social behaviour and health care utilization is complex. Frequent attendance is defined as a disproportionate amount of general practice consultation compared to the general public [36]. The evidence presented from various papers reviewed illustrates numerous ways in which personal health and good life affect the state of health and wellness of others [31]. The studies on the impact of social networks on health, the role of social support in determining individual health, and the spread of disease from one person to another have demonstrated the interconnectedness or interdependence of health among individuals in the society. In short, a person's illness, healthiness behaviour, infirmity, use of medical care facility, and death are related to similar outcomes in many other people that the person is associated with, and may have an abiotic spread of the disease. In the area of clinical and public health, the existence of social network health effects provides a strong theoretical and practical basis for the utilization and the healthiness of the people in the community. If a person's health outcome depends not only on his / her own biology and behaviour but also on the biology and behaviour of people around him/her, then collective intervention rather than individual intervention is particularly prominent. Social network groups exist to signify that individuals and events are interdependent, and health and healthcare can transcend individuals in ways that patients, doctors, decision-makers and researchers care about. The Chinese government vigorously promotes the family doctor policy system which requires everyone to have a family doctor especially for children and the elderly. The National Health and Family Planning Commission even has a system of assigning 
family doctors to families, yet many citizens are either ignorant of this requirement or have deliberately ignored it. Moreover, systemic constraints underpins why some residents do not have a registered family doctor. Firstly, the number of family doctors is not enough. The family doctors in China currently comprise of community GPs, retired doctors, and rural doctors. Since they also work as GPs, they do not have enough time and energy to work as family doctors with its peculiar demands. On the part of residents a common reason for low patronage is that many of them do not know the benefits the family doctor system can bring to them. Moreover sustained economic prosperity in China since its opening up in 1979, has led to richer citizens who have the means to afford high quality and exclusive care in big hospitals both at home and abroad.

\section{Conclusion}

The study affirms previous studies that suggest that social resources has the propensity to improve relationship between patients and clients and between doctors and peers for the benefit of the patients and the stability of the overall healthcare system. This underscores the need for healthcare managers to harness, nurture and sustain the different social network systems within the organization to support effective health service delivery. With diligence these social networks can be transformed into a multitude of social capital resources that can be optimized and deployed to support a robust, reliable, responsive, effective and efficient family care delivery across the healthcare delivery strata.

With China's strong collectivist culture, social capital is that it can help the Government to better promote and disseminate family doctor policies through the already established social network groups. Therefore understanding social capital or social network groups on the concept of family doctor system can promote and encourage residents to fully register and use family doctor services. The results of this review provide important rudimentary information for more advanced studies in the area of family doctor contract services in China and beyond. Firstly, while these study focuses on the extent to which social capital can play a role in patients desire to obtain family contract service, an emerging strand of literature equally suggest the reluctance of doctors to opt for family practice in China due to several factors. Some family doctors believe that an enormous demand is imposed by a bureaucracy that has little or no knowledge about the medical practice and it is not possible to protest. For example, the requirement for monitoring and evaluation of family doctors are perceived to be unfriendly and unsuitable to the healthcare industry even though they have been successfully applied in other industries. The need to stimulate practitioners to accept family doctor contract services is equally critical for the success of the venture and more systematic research is needed to advance the frontiers of knowledge in this regard.

Typical of academic studies a number of limitations may affect the findings of this research. Particularly this study focuses primarily on the interplay between social capital and family doctor contract services in China. This restriction severely limited the number of papers included (12) but also the scope regarding the potential of social capital. We recommend future research to consider widen the scope of research and explore other emerging benefits of social capital in family practice. For example, the rapid evolution of peer support networks established in conjunction with doctors is believed to be helping needy patients must be interrogated in a future studies.

Similarly, the studies were taken from only a few databases and supplemented with three additional sources. This implies that all other studies outside these sources were ignored. The small sample size of articles studied may limit the findings of this research. Relatedly, the strict inclusive and exclusive criteria used to select articles means that other articles with potentially useful information were deemed lowerquality, downgraded and disregarded. Further, the methodological limitations of the parent studies (particularly, regarding the sampling strategies of reviewed materials in the case of primary studies) limits the findings of the research. This is because most of these studies did not clearly indicate how participants in the studies were recruited and sampled and that may limit the transferability of the findings of this research. Even in the case of the secondary research based studies, the authors themselves have disclosed limitations regarding the process of sampling the studies which further limits any analysis made from them. This study included only articles published in English language and the coverage of the final set of admitted articles did not equally cover all the geographical areas of the world. This limits the generalizability of the findings to other contexts.

\section{Abbreviations \\ GPs: General practitioners; CASP: Critical appraisal skills programme; FDCS: Family doctor contract service.}

\section{Acknowledgments}

The support of colleagues and staff at the Department of Public Management of the School of Management and the Center for Health and Public Policy Research and the Overseas Education College of Jiangsu University is deeply appreciated. We are also grateful to the Zhenjiang Administration Bureau for Scientific and Industrial Research for their support 


\section{Authors' contributions}

$X X$ : Conceived the idea, collected the data, and revised the manuscript in line with the objectives. HAA: conducted the analysis of the data and drafted manuscript. LZ: is the supervisor of the project and sequentially aligned the parts of the research paper, AB: collected data and analyzed the data. TM: collected the data, conducted the analysis. All authors read and approved the final manuscript.

\section{Authors' information \\ XX:Holds a PhD in Management Science with research and teaching interest in Health Economics and Health Policy Management. He has 10 years of teaching and research experience in this area. He is currently a teacher at the School of Management at the Jiangsu University.}

LZ: Professor of Public Management, Dean of School of Management (Jiangsu University), and Head of Governing Board of Social Health Insurance in Jiangsu Province (PRC). He has 30 years of teaching and research experience and published articles in the field of Social Policy, Public Management and Healthcare Policy Management.

HAA: Holds a PhD in Management Science with a research interest in International Management, Public Management, and Health and Development Policy. He is currently a postdoctoral fellow of the Institute of Systems Engineering and a Senior Foreign Expert at the Centre for Health and Public Policy Research of Jiangsu University and the Shanghai Normal University. He has 10 years teaching and research experience in Management Science, Public Management and Development Policy.

AB: Holds a PhD in Development Studies and is a lecturer and Coordinator of Students Affairs at the School of Continuing and Distance Education of the University of Ghana and currently a postdoctoral fellow of the School of Management Jiangsu University. She has 10 years of teaching and research experience.

TM: Holds a PhD in Management Science with 8 years of teaching and research experience in Human Resource in Healthcare, Social Policy, and Healthcare Management. She is currently a Post-Doctoral Fellow of the Institute of Systems Engineering in Jiangsu University and Senior Foreign Expert of the at the Centre for Health and Public Policy Research of Jiangsu University.

\section{Funding}

The National Natural Science Foundation of China (71904066), the Social Science Foundation of Jiangsu Province(20SHD002) and the Universities' Philosophy and Social Science Researches in Jiangsu Province (2019SJA1884) provided assistance for pre-study, data collection and other administrative expenses incurred for the study as part of a larger project to evaluate the current state of family doctor contract services in selected provinces in China.

\section{Availability of data and materials}

The data for this research is held by the authors and will be made available upon reasonable request.

\section{Declarations}

\section{Ethics approval and consent to participate}

Ethical approval was granted by the Ethics Committee of the Center for Health and Public Policy Research of Jiangsu University China and confirmed by the Jiangsu University. This was approved by the Zhenjiang Administration Bureau for Scientific and Industrial Research. Written consent to participate was obtained from the study participants. The questionnaire included an opening statement explaining the ethical responsibilities of confidentiality of data, the anonymity of respondents, and participants responsibility to opt-out of the study at any time. Respondent's decision to fill the questionnaire constituted their consent to participate in the research-informed.

\section{Consent for publication}

Not applicable.

\section{Competing interests}

The author declares that there is no conflict of interest amongst them.

\section{Author details}

${ }^{1}$ School of Management, Jiangsu University, 301 Xuefu Road, Zhenjiang, Jiangsu, P.R. China. ${ }^{2}$ Center for Health and Public Policy Res, earch, Jiangsu University, 301 Xuefu Road, Zhenjiang, Jiangsu, P.R. China. ${ }^{3}$ Shanghai Normal University, 2151 Gongji Road, Pudongxin, Shanghai, P.R. China. ${ }^{4}$ School of Continuing and Distance Education, University of Ghana, P. O BoxLG25, Legon, Accra, Ghana.

Received: 20 August 2020 Accepted: 7 April 2021

Published online: 21 June 2021

\section{References}

1. Bataineh $H$, Devlin RA, Barham V. Social capital and having a regular family doctor: Evidence from longitudinal data. SocSci Med. 2019;220:421-9. https://doi.org/10.1016/j.socscimed.2018.12.003.

2. Binder A. For love and money: Organizations' creative responses to multiple environmental logics. Theory Soc. 2007;36(6):547-71. https://doi.org/ 10.1007/s11186-007-9045-x.

3. Bourdieu P, "The forms of Capital”, in J.G Richardson (ed.), Handbook of Theory and Research for the Sociology of Education. Westport: Greenwood Press; 1986.

4. Braun V, Clarke V. Using thematic analysis in psychology. Qual Res Psychol. 2006;3:77-101.

5. Calciolari S, González-Ortiz LG, Lega F. The influential role of personal advice networks on general practitioners' performance: A social capital perspective. BMC Health Serv Res. 2017;17(543). https://doi.org/10.1186/ s12913-017-2467-x

6. Campbell SM, McDonald R, Lester $\mathrm{H}$. The experience of pay for performance in english family practice: A qualitative study. Ann Fam Med. 2008;6(3):228-34. https://doi.org/10.1370/afm.844.

7. Coleman JS. Social capital, human capital, and investment in youth[M]. 1994.

8. Chandra S, Mohammadnezhad M, Ward P. Trust and Communication in a Doctor- Patient Relationship: A Literature Review. Journal of Healthcare Communications. 2018;3(36):1-6. https://doi.org/10.4172/2472-1654. 100146.

9. Critical Appraisal Skills Programme. Available from: https://casp-uk.net/ wp-content/uploads/2018/01/CASP-Qualitative-Checklist.pdf. Accessed 12 2019. (n.d.).

10. Devlin RA, Rudolph-Zbarsky J. Social networks and the probability of having a regular family doctor. SocSci Med. 2014;115:21-8. https://doi.org/ 10.1016/j.socscimed.2014.05.057.

11. Dinkel A, Schneider A, Schmutzer G, Brähler E, Häuser W. Family physician-patient relationship and frequent attendance of primary and specialist health care: Results from a German population-based cohort study. Patient EducCouns. 2016. https://doi.org/10.1016/j.pec.2016.02.009.

12. Due TD, Sandholdt H, Waldorff FB. Social relations and loneliness among older patients consulting their general practitioner. Dan Med J. 2017;64(3):1-6.

13. Ekawati FM, Claramita M, Hort K, Furler J, Licqurish S, Gunn J. Patients' experience of using primary care services in the context of Indonesian universal health coverage reforms. Asia Pac Fam Med. 2017;16(1):1-10. https://doi.org/10.1186/s12930-017-0034-6.

14. Fuertes JN, Mislowack A, Bennett J, Paul L, Gilbert TC, Fontan G, Boylan LS. The physician-patient working alliance. Patient EducCouns. 2007;66(1):29-36. https://doi.org/10.1016/j.pec.2006.09.013.

15. Gage-Bouchard EA. Social support, flexible resources, and health care navigation. SocSci Med. 2017;190:111-8. https://doi.org/10.1016/j.socsc imed.2017.08.015.

16. Greenwood N, MacKenzie A, Habibi R, Atkins C, Jones R. General practitioners and carers: A questionnaire survey of attitudes, awareness of issues, barriers and enablers to provision of services. BMC Family Pract. 2010;11(100). https://doi.org/10.1186/1471-2296-11-100.

17. Hanifan LJ. The Rural School Community Center. The ANNALS of the American Academy of Political and Social Science. 1916;67(1):130-8. https://doi.org/10.1177/000271621606700118.

18. Islam MK, Merlo J, Kawachi I, Lindström M, Gerdtham UG. Social capital and health: Does egalitarianism matter? A literature review. Int J Equity Health. 2006:5. https://doi.org/10.1186/1475-9276-5-3. 
19. Jacobs HH . Research Problems in Accident Prevention[J]. Social Problems. 1961;8(4):329-41.

20. Jing L, Shu Z, Sun X, Chiu JF, Lou J, Xie C. Factors influencing patients' contract choice with general practitioners in Shanghai: A preliminary study. Asia Pac J Public Health. 2015;27:77S-85S. https://doi.org/10.1177/10105 39514561654.

21. Junpeng L, Xian Z. Public Service Excellence in the 21st Century. In PublicService Excellence in the 21st Century. 2019. https://doi.org/10.1007/ 978-981-13-3215-9

22. Lucas PJ, Baird J, Arai L, Law C, Roberts HM. Worked examples of alternative methods for the synthesis of qualitative and quantitative research in systematic reviews. BMC Med Res Methodol. 2007;7:1-7. https://doi.org/ 10.1186/1471-2288-7-4.

23. Moore S, Haines V, Hawe P, Shiell A. Lost in translation: A genealogy of the "social capital" concept in public health. J Epidemiol Community Health. 2006;60(8):729-34. https://doi.org/10.1136/jech.2005.041848.

24. Moore S, Kawachi I. Twenty years of social capital and health research: A glossary. J Epidemiol Community Health. 2017;71(5):513-7. https://doi. org/10.1136/jech-2016-208313.

25. Noonan M, Doody O, Jomeen J, O'Regan A, Galvin R. Family physicians perceived role in perinatal mental health: An integrative review. BMC FamPract. 2018;19(1):1-22. https://doi.org/10.1186/s12875-018-0843-1.

26. Pasgaard AA, Mæhlisen MH, Overgaard C, Ejlskov L, Torp-Pedersen C, Bøggild $\mathrm{H}$. Social capital and frequent attenders in general practice: A register-based cohort study. BMC Public Health. 2018;18(310). https://doi. org/10.1186/s12889-018-5230-2.

27. Pluye P, Hong QN. Combining the power of stories and the power of numbers: mixed methods research and mixed studies reviews. Annual Rev Publ Health. 2014;35:29-45.

28. Rees A, Beecroft C, Booth A. Critical appraisal of the evidence. In K. Gerrish \& J. Lathleen (Eds.), The research process in nursing (7th ed., pp. 110-1). 2015a West Sussex: Wiley Blackwell;

29. Rees A, Beecroft C, Booth A. Critical appraisal of the evidence. The research process in nursing. (7th ed.; editors. In: Gerrish K, Lathleen J, Ed.). 2015b West Sussex: Wiley Blackwell;

30. Shang X, Huang Y, Li B, Yang Q, Zhao Y, Wang W., ... Qiu Y. Residents' awareness of family doctor contract services, status of contract with a family doctor, and contract service needs in Zhejiang Province, China: A cross-sectional study. Int J Environ Res Public Health. 2019;16. https://doi. org/10.3390/ijerph16183312.
31. Smith KP, Christakis NA. Social Networks and Health. Ann Rev Sociol. 2008;34(1):405-29. https://doi.org/10.1146/annurev.soc.34.040507. 134601.

32. Small EJ, Penson DF, Sartor O. The relationship between symptomatology and treatment selection in metastatic castrate-resistant prostate cancer[J]. Clin Adv Hematol Oncol H O. 2011;9(7):1-15.

33. Smith V, Begley CM, Clarke M, Devane D. Professionals' views of fetal monitoring during labour: A systematic review and thematic analysis. BMC Pregnancy and Childbirth. 2012;12. https://doi.org/10.1186/ 1471-2393-12-166.

34. Tsai J, Wilson M. COVID-19: a potential public health problem for homeless populations. Lancet Publ Health. 2020;5(4):e186-7.

35. Thoits PA. Mechanisms linking social ties and support to physical and mental health. J Health SocBehav. 2011;52(2):145-61. https://doi.org/10 1177/0022146510395592.

36. Vedsted P, Christensen MB. Frequent attenders in general practice care: A literature review with special reference to methodological considerations. Public Health. 2005;119(2):118-37. https://doi.org/10.1016/j.puhe.2004. 03.007.

37. Whittemore R, Knafl K. The integrative review: Updated methodology. J AdvNurs. 2005;52(5):546-53. https://doi.org/10.1111/j.1365-2648.2005. 03621.x.

38. Xu X, Zhou L, Asante-Antwi H. et al. Reconstructing family doctors' psychological well-being and motivation for effective performance in China: the intervening role of psychological capital. BMC Fam Pract. 2020;21:137. https://doi.org/10.1186/s12875-020-01182-1.

39. Yeo JH, Lee YG. Understanding the Association Between Perceived Financial Well-Being and Life Satisfaction Among Older Adults: Does Social Capital Play a Role? J Fam Econ Issues. 2019. https://doi.org/10.1007/ s10834-019-09634-2.

40. Zhou Z, Verdery AM, Margolis R, Chen F. No Spouse, No Son, No Daughter, No Kin in Contemporary China: Prevalence, Correlates, and Differences in Economic Support. Journals of Gerontology - Series B Psychological Sciences and Social Sciences. 2018;00(00):1-10. https://doi.org/10.1093/ geronb/gby051.

\section{Publisher's Note}

Springer Nature remains neutral with regard to jurisdictional claims in published maps and institutional affiliations.
Ready to submit your research? Choose BMC and benefit from:

- fast, convenient online submission

- thorough peer review by experienced researchers in your field

- rapid publication on acceptance

- support for research data, including large and complex data types

- gold Open Access which fosters wider collaboration and increased citations

- maximum visibility for your research: over $100 \mathrm{M}$ website views per year

At BMC, research is always in progress.

Learn more biomedcentral.com/submissions 